\title{
Pemahaman Dasar Hukum Perjanjian Hibah Melalui Penyuluhan di Desa Tempos, Kecamatan Gerung, Lombok Barat
}

\author{
Rinda Philona*, I Made Suradana, Novita Listyaningrum \\ Fakultas Hukum Universitas 45 Mataram \\ Jalan Imam Bonjol Cakranegara Kota Mataram NTB
}

\section{Article history}

Received: 06-10-2020

Revised: $15-11-2020$

Accepted: 24-11-2020

*Corresponding Author:

Rinda Philona,

Fakultas Hukum Universitas 45

Mataram, Mataram

Nusa Tenggara Barat,

Indonesia

Email:

rindakhansa@gmail.com

\begin{abstract}
Cooperation aims to import knowledge and understanding to the Tempos village people on the basic understanding of the law and grant convenant. Training is held by the cooperation of various parties: the combined small farm groups of tempos village and teachers of the law faculty of the university of 45 Mataram. Summary of counseling is conducted by the method of speech and discussion. All the supervisors followed the program in a fine way until it was finished and could even be said to be very enthusiastic by giving questions that olchs own village people of tempos had so far been able to conclude that the execution of this law was good and successfull in which the material could be handled so well.
\end{abstract}

Keywords: counseling; grant; rules

Abtrak: Kegiatan penyuluhan bertujuan untuk memberikan pengetahuan dan pemahaman kepada masyarakat Desa Tempos tentang Pemahaman Dasar Hukum Perjanjian Hibah. Kegiatan penyuluhan terselenggara berkat kerjasama berbagai pihak yaitu: Gabungan Kelompok Tani Desa Tempos dan Para Dosen Fakultas Hukum Universitas 45 Mataram. Krgiatan penyuluhan dilaksanakan dengan metode ceramah dan diskusi. Seluruh peserta penyuluhan mengikuti rangkaian acara dengan baik sampai selesai dan bahkan bisa dikatakan sangat antusias dengan memberikan berbagai macam pertanyaan yang seringnya dialami oleh para masyarakat Desa Tempos sendiri sehingga dapat diambil kesimpulan bahwa pelaksanaan peyuluhan hukum ini berjalan dengan baik dan sukses dimana materi yang disampaikan dapat terserap dengan baik oleh seluruh peserta dan peserta banyak mendapatkan pengetahuan tentang Dasar-dasar Hukum Perjanjian Hibah.

Kata Kunci: Penyuluhan; Hibah; Peraturan

\section{PENDAHULUAN}

Lombok Barat adalah sebuah Kabupaten di Provinsi Nusa Tenggara Barat dengan ibu kotanya yaitu: Gerung. Lombok Barat merupakan salah satu kabupaten yang sangat penting untuk Nusa Tenggara Barat, karena merupakan pusat pemerintahan diwilayah ini. Luasnya Kabupaten Lombok Barat sekitar 896,56 Km dengan jumlah penduduknya yang besar sekitar 713.848 jiw. Lombok Barat memiliki beberapa kecamatan salah satunya Gerung yang terdiri dari 11 Desa termasuk salah satunya Desa Tempos yang menjadi lokasi penyuluhan pengabdian kegiatan masyarakat kami. Desa Tempos memiliki beberapa permasalahan yang terjadi salah satunya masalah tanah dan warisan serta hibah 
yang menimbulkan polemik setelah pemberi hibah meninggal dunia atau pun masih hidup. Dapat diketahui bahwa hibah merupakan pemberian barang dengan tidak ada tukarannya dan tidak ada sebabnya (Sulaiman Rasjid, 1954). Sehingga hibah ini merupakan akad yang berisi pemberian sesuatu oleh seseorang atas hartanya kepada orang lain ketika dia masih hidup tanpa imbalan apapun. Akan tetapi yang sering terjadi bahwa permasalahan hibah ini muncul saat pemberi hibah meninggal dunia termasuk di masyarakat Tempos Lombok Barat. Pemahaman masyarakat Lombok Barat khususnya di Desa Tempos sangat minim terhadap hal ini oleh karena itulah permintaan untuk mengadakan penyuluhan hukum tentang Dasar-Dasar Perjanjian hibah.

\section{METODE}

Mitra Pelaksana: Acara penyuluhan ini terselenggara atas kerjasama: 1) Perangkat Desa Tempos Lombok Barat, 2). Gabungan Kelompok Tani Desa Tempos Lombok Barat 3).Dosen-Dosen fakultas Hukum Universitas 45 Mataram.

Peserta: Peserta aktif kegiatan penyuluhan hukum ini adalah: gabungan kelompok tani Desa Tempos dan beberapa warga masyarakat Desa Tempos beserta beberapa perangkat Desa Tempos.

Mekanisme Persiapan Acara: Kegiatan Penyuluhan Hukum ini bergandengan dengan penyuluhan Pertanian yang merupakan inisiasi dari ketua kelompok tani Desa Tempos yang menginginkan adanya penyuluhan hukum mengenai dasar-dasar hukum perjanjian hibah yang mana sering terjadi masalah khususnya di Desa Tempos. Oleh karena itu Dosen-Dosen fakultas Pertanian denganDosen-Dosen Fakultas Hukum mewujudkan pelaksanaan penyuluhan tersebut.

Tempat dan Waktu: Kegiatan penyuluhan ini berlangsung pada hari kamis tanggal 13 Agustus 2020 pada pukul 09.00 wita s/d selesai dan bertempat di : Aula Kantor Desa Tempos Lombok Barat.

Metode Pelaksanaan: Metode yang dipergunakan dalam kegiatan penyuluhan ini adalah metode ceramah, diskusi dan tanya jawab.

\section{HASIL DAN PEMBAHASAN}

\section{Realisasi Pemecahan Masalah}

Berdasarkan Pasal 1666 Kitab Undang Undang Hukum Perdata (BW): hibah merupakan pemberian oleh seseorang kepada orang lainnya secara Cuma-Cuma dan tidak dapat ditarik kembali, atas barang-barang bergerak (dengan akta notaris) maupun barang-barang tidak bergerak (dengan akta pejabat pembuat akta tanah-PPAT) pada saat pemberi hibah masih hidup.

Hibah merupakan kehendak bebas pemilik harta untuk menghibahkan kepada siapa saja yang ia kehendaki. Akan tetapi kebebasan selalu dibatasi dengan pihak lain. Didalam harta pemberi hibah, terdapat hak bagian mutlak anak sebagai ahli warisnya dan hak ini dilindungi oleh Undang-Undang. Dalam hak kewarisan islam, pemberian hibah untuk orang lain, dibatasi sebesar 1/3 harta, jadi jika memang hibah melanggar hak anak, maka anak dapat menggugat pemberian hibah. Namun apabila anak tidak mempermasalahkan hibah dapat dilaksanakan. Guna mencegah terjadinya tuntutan dikemudian hari, dalam praktik disyaratkan adalah surat persetujuan dari anak kandung pemberi hibah 
atau ahli waris dan pemberi hibah tidak melanggar hak mutlak mereka. Hak mutlak adalah: bagian warisan yang telah ditetapkan oleh Undang-Undang untuk masing-masing ahli waris (pasal $913 \mathrm{bw}$ )

Untuk muslim tunduk pada aturan Pasal 209 Kompilasi Hukum Islam Penegasan SKB MA dan Menteri Agama No.07/KMA/1985 dan Qs Al-Ahzab (33):4-5 : bahwa pemberian hibah harus taat pada ketentuan batas maksimal sebesar 1/3 dari seluruh harta pemberi hibah. Untuk non muslim akan tunduk pada aturan pasal 881 ayat 2 BW yang mengatakan bahwa: dengan sesuatu pengangkatan waris atau hibah yang demikian yang mewariskan dan menghibahkan tak boleh merugikan ahli warisnya yang berhak atas sesuatu bagian mutlak.

\section{Unsur-Unsur Hibah:}

1. Hibah merupakan perjanjian sepihak yang dilakukan dengan Cuma-Cuma artinya tidak ada kontra prestasi dari penerima hibah;

2. Dalam hibah selalu diisyaratkan bahwa penghibah mempunyai maksud untuk menguntungkan pihak yang diberi hibah;

3. Objek perjanjian hibah : segala macam harta benda milik penghibah, baik berwujud maupun tidak berwujud, benda tetap maupun bergerak

4. Dilakukan saat penghibah masih hidup

5. Harus dilakukan didepan akta notaris.

\section{Rukun Hibah}

1. Ada ijab kabul yang menunjukkan ada pemindahan hak milik seseorang (yang menghibahkan) kepada orang lain (yang menerima hibah);

2. Ada orang yang menghibahkan dan yang akan menerima hibah, disyaratkan bahwa yang diserahkan benar-benar milik pemberi hibah secara sempurna dan pemberi hibah harus orang yang cakap untuk bertindak menurut hukum;

3. Ada harta yang akan dihibahkan, harta itu milik pemberi hibah secara sempurna dan merupakan harta yang bermanfaat serta diakui agama.

\section{Syarat Hibah}

1. Bagi para pemberi hibah :

a. Pemberi hibah bukan orang yang dibatasi haknya oleh suatu alasan.

b. Pemberi hibah adalah orang yang cakap bertindak menurut hukum (dewasa dan tidak kurang akal)

c. Barang yang dihibahkan adalah milik si pemberi hibah

d. Pemberi hibah tidak dipaksa memberikan hibah.

2. Bagi penerima hibah: bahwa penerima hibah haruslah orang yang ada pada waktu hibah dilaksanakan.

3. Syarat benda yang dihibahkan :
a. Benda tersebut benar-benar ada
b. Benda tersebut mempunyai nilai
c. Benda tersebut dapat dimiliki zatnya, diterima peredarannya dan pemilikannya dapat dialihkan
d. Benda yang dihibahkan dapat dipisahkan dan diserahkan kepada penerima hibah. 
Dalam praktik pelaksanaan diIndonesia, khususnya penghibahan atas barang-barang yang tidak bergerak, seperti penghibahan atas tanah dan rumah, selalu dipedomani ketentuan yang termaktub dalam Pasal 1682 dan 1687 Kitab Undang-Undang Hukum Perdata, yaitu adanya suatu formalitas dalam bentuk akta Notaris, hal ini kaitannya dengan pengurusan surat-surat balik nama atas bendabenda tersebut. Sedangkan apabila benda-benda yang dihibahkan tersebut berbentuk tanah yang sudah mempunyai sertifikat, maka penghibahan harus dilakukan didepan Pejabat Pembuat Akta Tanah (PPAT) didaerah mana tanah tersebut berada. Penghibahan atas barang-barang bergerak tidak ada formalitas yang harus diikuti, dan sah dilakukan dengan cara menyerahkan langsung barang tersebut kepada penerima hibah, atau orang lain yang bertindak untuk atas nama penerima hibah, dan seketika itu juga telah terjadi perpindahan hak dari hak pemberi hibah kepada penerima hibah.

Terdapat beberapa hal yang dapat menyebabkan hibah menjadi batal antara lain:

1. Hibah yang mengenai benda-benda yang baru akan ada dikemudian hati (Pasal 1667 ayat (2) KUHPerdata)

2. Hibah dengan mana si penghibah memperjanjikan bahwa ia tetap berkuasa untuk menjual atau memberikan kepada orang lain suatu benda yang termasuk dalam hibah, dianggap batal. Yang batal hanya terkait dengan benda tersebut ( Pasal 1668 KUHPerdata)

3. Hibah yang membuat syarat bahwa penerima hibah akan melunasi utang atau beban-beban lain disamping apa yang dinyatakan dalam akta hibah itu sendiri atau dalam daftar dilampirkan ( Pasal 1670 KUHPerdata)

4. Hibah atas benda tidak bergerak menjadi batal jika tidak dilakukan dengan akta notaris (Pasal 1682 KUHPerdata).

Dengan demikian, selama hibah tersebut telah diterima si penerima hibah sebelum ia meninggal dunia (walaupun penerima hibah meninggal terlebih dahulu dari pemberi hibah), maka hibah tersebut adalah sah.

Berdasarkan hal-hal diatas merupakan materi yang disampaikan oleh kami selaku penyuluh untuk menjawab akan permasalahan yang ditanyakan oleh beberapa peserta aktif yang mana dalam pelaksanaan hibah sesuai dengan hukum yang berlaku, bahwa dalam pelaksanaan harus mengikuti kaidah hukum agar penerima hibah memiliki kekuatan hukum yaitu: melaksanakan akad dihadapan notaris untuk mendapatkan bukti otentik yang dimiliki apabila terjadi permasalahan dikemudian hari. Selain daripada itu kami juga mengarahkan apabila terjadi permasalahan hukum terutama mengenai hibah masyarakat Desa Tempos dapat berkonsultasi pada Lembaga Bantuan Hukum bertempat diUniversitas 45 Mataram.

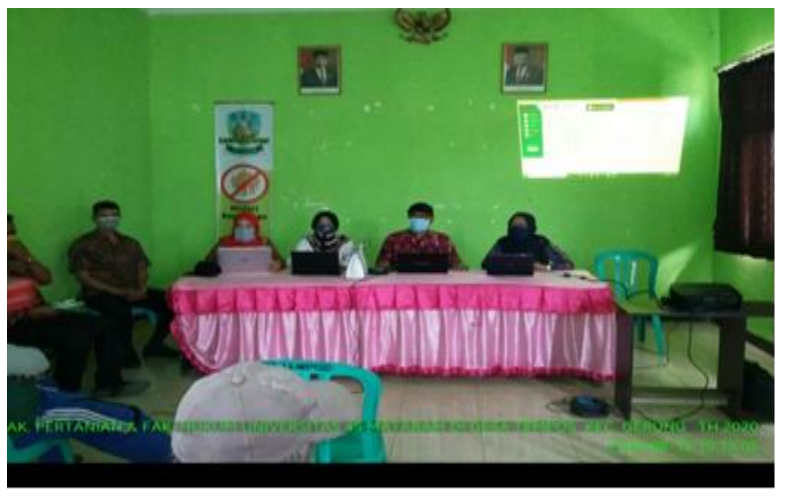

Gambar 1. Para penyuluh yang memberikan materi penjelasan kepada peserta penyuluhan ini

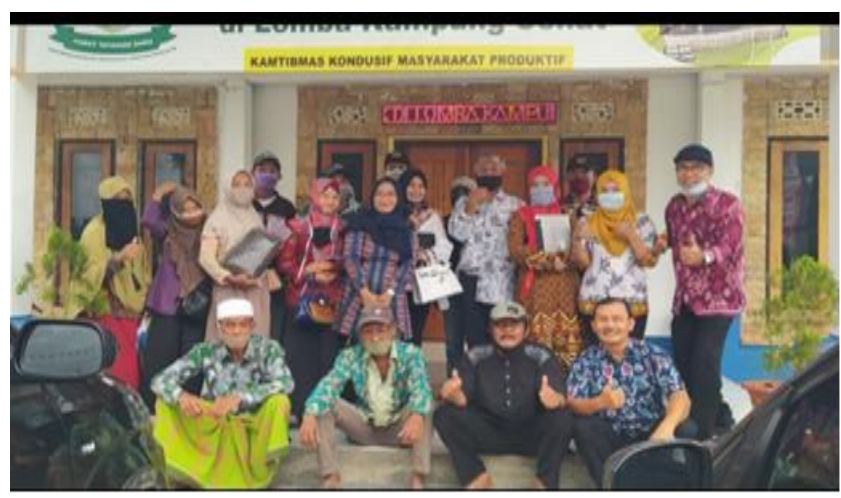

Gambar 2. Para penyuluh bersama Kepala Desa Tempos dan warga Desa Tempos Gerung Lombok Barat 


\section{KESIMPULAN DAN SARAN}

Berdasarkan kegiatan penyuluhan hukum dilaksanakan di Desa Tempos dilaksanakan membawa dampak positif dimana masyarakat jadi lebih mengetahui prosedur dan kekuatan hukum dari pelaksanaan hibah agar meminimalisir efek masalah yang terjadi kedepannya dan dapat dilihat bahwa kegiatan penyuluhan ini perlu terus dilaksanakan dan ditingkatkan agar pemahaman masyarakat lebih banyak tentang Hirarki peraturan perUndang-Undangan dan lebih memahami akan segala tindakan

\section{Ucapan Terima Kasih}

Sesuai dengan pelaksanaan kegiatan penyuluhan hukum ini dilaksanakan kami ingin mengucapkan rasa terimakasih kepada : Universitas 45 Mataram yang telah memberikan izin untuk dapat melaksanakan kegiatan ini, selain daripada itu kami mengucapakn rasa terimakasih sebesar besarnya kepada Keapal desa Tempos beserta jajarannya yang mendukung kegiatan ini berlangsung serta memberikan waktu dan tempat bagi susksesnya kegiatan dan juga kami berterimakasih pada kelompok tani beserta masyarakat Desa Tempos lainnya sebagai peserta aktif guna peran sertanya mengikuti kegiatan sampai selesai dengan penuh antusias dan memerikan kesan yang baik.

\section{DAFTAR PUSTAKA}

Chairuman Pasaribu, Suhrawardi K Lubis, Hukum Perjanjian Dalam Islam, Jakarta: Sinar Grafika, 2004

Sulaiman Rasjid, Fiqh Islam, Jakarta: At Tahiriyah, 1954.

Tobing Latezzia Keabsahan Hibah, Hukum Online.

Wikipedia.org, Kabupaten Lombok Barat

Wikipedia.org, Tempos, Gerung Lombok Barat 